\title{
A New Method of Preparing Highly Conductive Ultra-Thin Indium Tin Oxide for Plasmonic-Enhanced Thin Film Solar Photovoltaic Devices
}

Jephias Gwamuri $^{\mathrm{a}}$, Ankit Vora ${ }^{\mathrm{b}}$, Jeyanthinath Mayandi ${ }^{\mathrm{a}, \mathrm{c}}$, Durdu Ö. Güney ${ }^{\mathrm{b}}$, Paul L. Bergstrom ${ }^{\mathrm{b}}$, Joshua M. Pearce ${ }^{a, b^{*}}$

${ }^{a}$ Department of Materials Science \& Engineering, Michigan Technological University, 1400 Townsend Dr., Houghton, MI, 49931-1295, U.S.A.

${ }^{\mathrm{b}}$ Department of Electrical \& Computer Engineering, Michigan Technological University, 1400 Townsend Dr., Houghton, MI, 49931-1295, U.S.A.

${ }^{\mathrm{c}}$ Department of Materials Science, School of Chemistry, Madurai Kamaraj University, Tamil Nadu, Madurai -625 019, India.

* Contact author: 601 M\&M Building, 1400 Townsend Drive, Houghton, MI 49931-1295, Ph:906-487-1466 pearce@mtu.edu

\begin{abstract}
Recent numerical modeling of plasmonic metallic nanostructures have shown great potential as a method of light management in thin-film nanodisc-patterned hydrogenated amorphous silicon (a$\mathrm{Si}: \mathrm{H}$ ) solar photovoltaic (PV) cells. A significant design challenge for such plasmonic-enhanced PV devices is the requirement for ultra-thin transparent conducting oxides (TCOs) with high transmittance (low loss) and low enough resistivity to be used as device top contacts/electrodes. Most work on TCOs is on relatively thick layers and the few reported cases of thin TCO showed a marked decrease in conductivity. Recent work on ultra-thin TCOs of aluminum-doped zinc oxide, indium-doped tin oxide and zinc oxide revealed an unavoidable trade-off between transmittance and resistivity when fabricated with conventional growth methods. Ultra-thin films showed a tendency to be either amorphous and continuous or form as isolated islands. This results in poor electrical properties, which cannot be improved with annealing as the delicate thin films nucleate to form grain clusters. In order to overcome this challenge, this study investigates a novel method of producing ultra-thin $(<40 \mathrm{~nm})$ high quality TCOs. First, $\sim 80 \mathrm{~nm}$ ITO films are sputtered in various argon-oxygen atmospheres and annealed to increase conductivity. The most promising materials were then reduced in thickness with a controlled low-cost room-temperature cyclic wet chemical etching process to reach the desired thickness. The degradation in the electrical conductivity was tracked as a function of thickness. The sheet resistance of $36 \mathrm{~nm}$ thin films was observed to be of the same order compared to the much thicker commercial ITO films currently used as transparent electrodes in PV and other opto-electronic devices. Experimental optical properties of the shaved films were then used in an optimized model of nano-disc plasmonic a-Si:H solar cells. Simulations indicate that optical enhancement greater than $21 \%$ are possible in the $300-730 \mathrm{~nm}$ wavelength range, when compared to the reference cell. Using the novel chemical shaving method described here, high-quality ultra-thin ITO films capable of improving the efficiency of thin film a-Si:H solar cells have been demonstrated. The methods employed in the optimization process are well established and economically viable, which provide the technical potential for commercialization of plasmonic based solar cells.
\end{abstract}

Keywords: transparent conducting oxide; indium tin oxide; plasmonic, photovoltaic; amorphous silicon; optical enhancement 


\section{Introduction}

To increase the efficiency of solar photovoltaic (PV) cells while reducing costs, several light management schemes have been proposed and investigated, such as metal nano-particles, nanowires, and plasmonic metallic nanostructures (metal-insulator-metal (MIM)/ insulatormetal-insulator (IMI)) [1 - 7]. The lowest cost per unit power can be obtained with thin film hydrogenated amorphous silicon $(\mathrm{a}-\mathrm{Si}: \mathrm{H}) \mathrm{PV}$ [8]. Although a-Si:H is a thin film material with a direct mobility gap, the Staebler-Wronski Effect or light induced degradation effectively limits the intrinsic layer thickness [9-13]. Thus, historically light trapping was first applied to a-Si:H $[14,15]$ and remains important today to improve device performance. Modeling studies of plasmonic metallic nanostructures have shown great potential as a light management scheme in thin-film nanodisc-patterned a-Si:H solar cells [16]. Their ability to sustain coherent electronic oscillations leading to electromagnetic field coupling and confinement [17] has made plasmonic enhancement an area with very high prospects for light harvesting in PV devices [18, 19]. A number of technical and fabrication related issues act as a barrier to the full realization of plasmonic based commercial grade PV devices. Parasitic optical absorption (ohmic losses) in the metallic structure and high carrier recombination near the metal-semiconductor interfaces remain significant challenges [16, 20-22].

The most prominent fabrication challenge is the complication of scalable and economically viable techniques for controlled nanostructure patterning. The fact that plasmonic resonances are highly dependent on both shape and geometry of nanostructures [23] means that design parameters should be highly controlled throughout the fabrication process. Another design challenge for plasmonic enhanced PV devices, such as the one proposed by Vora, et al. [16], is the requirement for ultra-thin transparent conducting oxides (TCOs) with high transmittance (low loss) and low enough resistivity to be used as device top contacts/electrodes [20]. Most work on TCOs is on relatively thick layers [24] and the few reported cases of thin TCO showed a marked decrease in conductivity [25]. Recent work on ultra-thin TCOs (aluminum-doped zinc oxide (AZO), indium-doped tin oxide (ITO) and zinc oxide ( $\mathrm{ZnO}$ )) [20] revealed an unavoidable trade-off between the transmittance and resistivity and the challenge to strike a balance between optical and electrical parameters of different TCOs when fabricated with conventional growth methods. Ultra-thin films showed a tendency to be either amorphous and continuous or as isolated islands, which explained the observed poor electrical properties. Improving the electrical properties of these films through annealing proved ineffective since the delicate thin films would nucleate to form grain clusters.

In order to overcome this challenge, this study investigates a novel method of producing continuous ultra-thin $(<40 \mathrm{~nm})$ TCOs. First $\sim 80 \mathrm{~nm}$ ITO films are sputtered in various argonoxygen atmospheres and annealed to increase conductivity. These films were then characterized optically and electrically. The most promising materials were then reduced in thickness with a well-controlled low-cost chemical etching process to reach the desired thickness. The degradation in the electrical conductivity was tracked as a function of thickness.

\section{Material and methods}

This study focus was on achieving thinner ITO films $(<40 \mathrm{~nm})$ with optimal optical and electrical properties to be used both as a buffer layer and as the top contact for the solar cell 
structure proposed by [16] and is shown in Fig. 1. Film processing was done by RF sputter deposition techniques (Perkin-Elmer Model 2400) [26, 27]. The approach used was to grow films with a targeted thickness of $80 \mathrm{~nm}$ and then reduce the thickness to $<40 \mathrm{~nm}$. Thin films were grown on (100) prime silicon substrates with a $98 \mathrm{~nm}$ thermally grown oxide, and on glass substrates using a $99.99 \% 100 \mathrm{~mm}$ diameter pressed ITO ( $\mathrm{Sn}_{2} \mathrm{O}: \mathrm{In}_{2} \mathrm{O}_{3} 10: 90 \%$ wt.) target. Substrates were ultrasonically cleaned in isopropanol for 15 minutes followed by another 15 minutes in DI water $(17.2 \mathrm{M} \Omega-\mathrm{cm})$ before they were dried using $\mathrm{N}_{2}$. The sputtering chamber was initiated to a low $10^{-7}$ Torr base pressure to minimize ambient condition impact on the resulting films. The sputtering process pressure was maintained at $7.5 \times 10^{-3}$ Torr. The distance between the target and substrates was kept constant. As a standard procedure, the target was pre-sputter cleaned at a power of $150 \mathrm{~W}$, whereas the sputter deposition of the films was performed at $100 \mathrm{~W}$. The argon gas flow was maintained at approximately $10 \mathrm{sccm}$ to attain the targeted processing pressure, and the oxygen gas flow was varied as listed in the Table 1. The sputter deposition rate was estimated to be in the range of 8-12 nm per minute, depending upon the oxygen flow rate.

Processed samples were cleaved and one part was annealed at $300^{\circ} \mathrm{C}$ for $30 \mathrm{~min}$. in air to increase the crystallinity following the success of various reports [24,25]. Both as-deposited and annealed sample sets were then optically and electrically characterized to determine sample thicknesses, optical constants $n$ and $k$, and sheet resistance (to obtain the resistivity). The optical properties were obtained using variable angle spectroscopic ellipsometry (VASE) (J.A Woollam Co UV-VIS V-VASE with control module VB-400). Electrical characterization was performed using a four point probe system consisting of ITO optimized tips with 500 micron tip radii set to 60 grams pressure and an RM3000 test unit from Jandel Engineering Limited, UK. In addition, structural properties for the selected films of lower sheet resistance and higher optical properties were investigated by X-ray diffraction (XRD) (Scintag 2000). The XRD were done for both the as-deposited and annealed ITO samples deposited on glass substrates.

The resistivity and transmittance measurements were also performed on samples deposited on glass, whereas the thicknesses were measured from the $\mathrm{Si} / \mathrm{SiO}_{2} / \mathrm{ITO}$ samples. Films with the transmittance values greater than $75 \%$ and resistivity values within the $10^{-4} \Omega$-cm range after annealing were selected for further processing. From Table 1, samples A2 (both on glass and $\mathrm{Si} / \mathrm{SiO}_{2}$ ) were subjected to the etching process using a standard chemical etchant for etching ITO. A mixture of $\mathrm{HCl}: \mathrm{HNO}_{3}: \mathrm{H}_{2} \mathrm{O}(1: 1: 5)$ volume ratio [28] was prepared and used for etching sample A2. All the etching was performed at room temperature, resulting in a slow and controlled etch rate for the $\mathrm{Si} / \mathrm{SiO}_{2}$ films. Etched samples were then thoroughly rinsed in DI water before they were dried in $\mathrm{N}_{2}$ and subjected to optical and electrical characterization. The etch times were varied and the process repeated with a subsequent optical and electrical measurements between each etch. The surface morphology of the sample A2, as deposited, annealed and after etching were also investigated using an atomic force microscopy (Veeco Dimension 3000).

\section{Theory/calculation}

The complex relative permittivity (of the form $\varepsilon_{\mathrm{r}}=\varepsilon^{\prime}-\mathrm{j} \varepsilon^{\prime \prime}$ ) of $p$-a-Si:H, $i$-a-Si:H, $n$-a$\mathrm{Si}: \mathrm{H}$, and aluminum doped zinc oxide (AZO) of an a-Si:H solar cell (fabricated by ThinSilicon, Mountain View, CA) (Fig. 1) were measured using a J.A. Woollam variable-angle spectroscopic ellipsometer. The complex relative permittivity of both silver and silicon nitride $\left(\mathrm{Si}_{3} \mathrm{~N}_{4}\right)$ were taken from Palik [29] and the ITO optical properties were obtained from characterization of locally processed/optimized samples. The optical responses of the nano-disk patterned solar cell (NDPSC) was calculated through a fully-vectorial finite element based software package 
COMSOL Multiphysics RF module v5.0 in frequency domain. The NDPSC solar cell structure [16] was simulated using periodic boundaries for the vertical sides and excitation and output ports were used above and below the suspended air of the unit cell respectively. The absorbance in the $i$-a-Si:H layer was calculated from the power loss density function in COMSOL, which in turn was used to calculate theoretical absorbed power density in the $i$-a-Si:H layer of NDPSC and the reference using MATLAB r2013b as described by Vora, et al. [16] for the incident AM 1.5 reference solar spectrum using the equation:

$P_{i-a-S i: H}=\int A(\lambda) E_{A M 1.5}(\lambda) d \lambda$

where $P_{i-a-S i: H}$ is the absorbed power density $\left(\mathrm{W} / \mathrm{m}^{2}\right)$ in the $\mathrm{i}-\mathrm{a}-\mathrm{Si}: \mathrm{H}$ layer, $A(\lambda)$ is the absorbance in i-a-Si:H layer as a function of wavelength, and $E_{A M 1.5}(\lambda)$ is the spectral irradiance as a function of wavelength (obtained from NREL [30]. The optical enhancement (OE) is calculated using the equation:

$O E=\left(P_{i-a-S i: H(N D P S C)} / P_{i-a-S i: H(\operatorname{Ref})}-1\right) \times 100$

where the subscript 'NDPSC' and 'Ref' denote NDPSC and reference cell, respectively.

\subsection{Results}

\subsection{Electrical and optical characterization}

The resistivity in ohm-cm for the as-deposited and annealed samples after $30 \mathrm{~min}$ at $300^{\circ} \mathrm{C}$ are summarized in Table 1 . The as-deposited values are presented here only for comparison purposes. As is observed in Table 1, sample A2 has the lowest resistivity value of $5.5 \times 10^{-4} \Omega$-cm and a fairly high average transmittance of $79 \%$ for the annealed samples, hence it was chosen for further processing. The transmittance is expected to improve as the film thickness is decreased through etching whilst the resistivity is expected to show an inverse variation with thickness for the same film sample (A2).

Fig. 2 (a) and (b) depicts the resistivity and transmittance versus the oxygen flow rate of the selected samples deposited on glass substrates. The effect of oxygen content on the resistivity of sputter deposited films is well documented [24,25]. Accordingly, each sputter deposition system varies in its optimal range of process gas composition. In the system used for this study, it was found that the lowest resistivity $1.79 \times 10^{-03} \Omega-\mathrm{cm}$ is obtained for the as-deposited samples processed with an oxygen flow rate of $0.3 \mathrm{sccm}$. Relatively, the as-deposited films without oxygen and with other flow rates show an order of magnitude difference in resistivity. Optical measurements show that an oxygen flow of 0.4 to $0.5 \mathrm{sccm}$ gives as-deposited samples films with higher transmittance of about $85 \%$ in the visible wavelength range $(400-800 \mathrm{~nm})$.

Post processing annealing of samples in air at $300^{\circ} \mathrm{C}$ for 30 minutes results in a substantial improvement in the resistivity and the transmittance as shown in the Table 1 . The lowest resistivity values are obtained for the cases of 0.2 and $0.3 \mathrm{sccm}$ oxygen flow and were recorded at $5.5 \times 10^{-4}$ and $5.7 \times 10^{-4} \Omega$-cm, respectively. The average transmittance for the same samples in the 400-800nm wavelength range showed $\sim 10 \%$ difference and $0.2 \mathrm{sccm}$ gave samples with a better transmittance than those deposited with oxygen flow rates of 0.3 and 0 sccm. It was observed that films processed at higher oxygen flow rates $(0.4$ and $0.5 \mathrm{sccm})$ showed about $90 \%$ transmittance. However, these same samples had a higher resistivity 
compared to the other samples and therefore are not appropriate for use as top contact for the proposed high efficiency plasmonic based a-Si:H PV device.

\subsection{XRD analysis}

XRD spectra for the as-deposited and annealed sample sets with various oxygen flow deposited on glass is illustrated in Figs. 3 (a) and (b). The raw data was corrected for base line using the Origin software. The data was smoothened before it was presented for analysis. The results indicate that the as-deposited films show a polycrystalline nature with some amorphous tendency. For all conditions, the (222) peak is pronounced and clearly defined, whereas the (400) and (441) peaks were not present for the as-deposited film with $0.2 \mathrm{sccm}$ oxygen, but it is clearly present for the other deposition cases. The annealed samples show the presence of the (222), (400), and (441) peaks, and a weak (622) peak for the case of films deposited with 0.2 to $0.5 \mathrm{sccm}$ oxygen. More details such as lattice constants, $\mathrm{d}$-spacing and grain size that are extracted from the XRD are summarized in Table 2. It is well known that ITO deposited with the $\mathrm{Ar}+\mathrm{O}_{2}$ composition will have the preferred orientation of (222) and (400) [24].

The intensity ratios $\left(\mathrm{I}_{222} / \mathrm{I}_{400}\right)$, for the materials with various oxygen flow and annealing has the values of 1.93 to 4.68 as listed in Table 2 and shown in Fig. 4. The figure clearly indicates the large variation in the intensity ratio and thus the microstructure. The estimated grain size for the lowest oxygen flow cases was observed to increase for the annealed samples whilst for the other cases, the grain size decreased after annealing. Worth noting is the case for the 0.3 sccm sample, where the grain size drastically decreased after annealing (Table 2). By comparing the results with the intensity ratio of standard indium oxide (3.33), the high and low intensity ratios were observed for all of the materials.

\subsection{Chemical Shaving: Cyclic Wet Chemical Etching}

In this study, the samples with $0.2 \mathrm{sccm}$ (A2) were used for the etching. The sample were etched at various times in the prepared etchant for several cycles and measured for the resistivity and thickness between each cycle. The obtained results are summarized in Table 3. Figs. 5 (a) and (b) represent the etching time versus thicknesses and thickness versus resistivity for the measured sample. The samples were etched from $85 \mathrm{~nm}$ to $36 \mathrm{~nm}$ in 7 cycles with varying etching times. The variation in the resistivity corresponding to the remaining thickness were monitored and listed in Table 3. As the thickness of the film decreases the resistivity increases, but for the cycles etched we found that the resistivity is still in the order of $10^{-4} \Omega-\mathrm{cm}$. Chemical shaving was stopped after achieving a $36 \mathrm{~nm}$ film since this film showed desirable electrical properties and managing thinner films was going to be a challenge. 


\subsubsection{AFM Analysis}

The AFM analysis showed that the etching process was quite uniform throughout the etched samples. There was no visible change in grain size with etching indicating that the annealed films were homogeneously micro-crystalline in nature with no evidence of an amorphous layer.

Fig. 6 (a) shows the AFM images of the ITO sputtered film on silicon with oxide layer with different process as described in the figure caption. Roughness values were taken from the area of 3000 x $3000 \mathrm{~nm}$ and shown in Fig. 6(e). As can be seen in Fig. 6 there was a change in the surface morphology of the samples before and after etching. The root means square (rms) surface roughness of 2.4, 2.7 and $8.5 \mathrm{~nm}$ for the as-deposited and annealed, $30 \mathrm{sec}$. and $660 \mathrm{sec}$. etched samples was observed respectively.

\subsubsection{Optical Inspection}

Fig. 7 depicts the optical microscope image of the ITO surface for the as deposited (a) and for the annealed and etched films (b), respectively. The optical microscope inspection of the ITO surface of the as-deposited film on the $\mathrm{Si} / \mathrm{SiO}_{2}(98 \mathrm{~nm})$ substrates shows a smooth surface with some defects locally that may be due to the substrate. The initial Si substrate had a $98 \mathrm{~nm}$ film of $\mathrm{SiO}_{2}$ (blue in color) was sputtered with an ITO film of about $\sim 80 \mathrm{~nm}$. Thus, Fig. 7 (a) shows a reflection of greenish in color, after the film is etched down to about $35 \mathrm{~nm}$, the film becomes transparent enough for the bluish color of $\mathrm{SiO}_{2}$ layer below to be visible. The color uniformity can be directly correlated to the film uniformity as already confirmed from the AFM characterization.

\subsection{Optical Simulation}

The optical simulation results are discussed below. Simulations for absorbance in the $i$-a$\mathrm{Si}: \mathrm{H}$ were carried out for the solar cell with device structure as shown in Fig. 1a and b. Optical parameters used in the simulation were obtained from subsequent chemical shaving cycles and fed into an optimized model to study the enhancement behavior of the device. The ITO layer was systematically increased from $36 \mathrm{~nm}$ to $81 \mathrm{~nm}$ for all film thicknesses shown in Table 3 without changing the underlying parameters of other layers and nano-disk. The absorbance and the absorbed power density in the $i$-a-Si:H layer was recorded for each measured thickness as seen in Fig. 8.

Results from simulation for absorbance in a solar cell with ITO spacer layer for thickness ranging from $36-81 \mathrm{~nm}$ are shown in Fig. 8 (a). The effect of ITO layer thickness on the absorbed solar radiation in the $300-730 \mathrm{~nm}$ spectral range is evident and the $36 \mathrm{~nm}$ thick ITO film offers the best overall enhancement. Fig. 8 (b) shows the dependence of absorbed power density in $i$-a-Si:H on ITO thickness. Absorption is highest $\left(\sim 270 \mathrm{~W} / \mathrm{m}^{2}\right)$ when the ITO layer between the plasmonic nano-discs and the $p$-a-Si:H is thinnest $(36 \mathrm{~nm})$ and lowest $\left(220 \mathrm{~W} / \mathrm{m}^{2}\right)$ for $81 \mathrm{~nm}$ ITO. Fig. 8 (c) shows how optical enhancement in $i$-a-Si:H varies with ITO layer thickness for two reference cells; one with ITO top layer of $70 \mathrm{~nm}$ and the other with $80 \mathrm{~nm}$. Both reference cells have no nano-disc plasmonic structure (Fig. 1(b)).

\section{Discussion}


Simulation results show a theoretical enhancement of $21 \%$ from the proposed cell structure (Fig. 1) with the locally fabricated and optimized $36 \mathrm{~nm}$ ITO film. These results provide a clear opportunity for improving a-Si:H PV efficiency and should be pursued for future work. Electrical characterization confirms a clear dependence of sheet resistance on the reactive gas composition as shown in Fig. 2. There is a marked increase in sheet resistance as the oxygen concentration increases for the as-deposited films. However, annealing the films in air for 30 minutes results in a large decrease in the sheet resistance for the 0.3 and $0.4 \mathrm{sccm}$ oxygen gas flow rates. Evidently, the annealed films are more crystalline in nature unlike the as-deposited films, which exhibit a predominantly amorphous microstructure. AFM images are also presented to compliment the XRD results. As has been previously reported, annealing improves film homogeneity as it provides sufficient energy to allow the Sn atoms to diffuse into the indium oxide matrix. This has the effect of decreasing the overall lattice disorder resulting in an increase in carrier mobility [31]

These observed diffraction lines agree with cubic bixbyite indium oxide structure JCPDS card No: 06-0416 and la-3 space group (Number: 206). Impurity of Sn phases is not observed in the XRD spectrum in the deposited and annealed films. It is evident from these results that the $\mathrm{Sn}$ atoms occupy the substitution sites of the indium atoms. In general, the intensities ratio was responsible for the combination of $\mathrm{In}^{3+}$ and $\mathrm{O}^{2-}$ ions in the ITO films [24]. This type of pairing enhances the indium oxide network formation and maintains the periodicity of the indium oxide. A critical level of $\operatorname{~In}^{3+}$ and $\mathrm{O}^{2-}$ pairs are required for the formation of these networks. Below the critical level, defects in the indium oxide films will result. Hence the peak intensities of the films are greatly influenced by these combinations as reflected in the XRD spectra in Fig. 3. ITO films with thicknesses greater than $100 \mathrm{~nm}$, have been well studied and documented [32-33]. However, their properties cannot be extrapolated to films of thickness $90 \mathrm{~nm}$ and below due to significant and unpredicted microstructures associated with these ultra-thin films [20].

\section{Conclusions}

Cyclic wet chemical etching performed at room temperature was used to thin ITO films from $81 \mathrm{~nm}$ down to $36 \mathrm{~nm}$. The films were characterized at the end of each cycle for electrical and optical properties. The sheet resistance of the thinnest film $(36 \mathrm{~nm})$ was observed to be on the same order as much thicker commercial ITO films currently utilized as transparent electrodes in PV and other opto-electronic devices. Optical properties of the shaved films were used in an optimized model to predict the optical enhancement of nano-disc plasmonic a-Si:H solar cells. Simulations indicate that optical enhancement greater than $21 \%$ are possible in the $300-730 \mathrm{~nm}$ wavelength range when compared to the reference cell. Using the novel chemical shaving method described here, high-quality ultra-thin ITO films capable of improving the efficiency of thin film a-Si:H solar cells have been demonstrated. The methods employed in the optimization process are well established and economically viable, which provide the technical potential for commercialization of plasmonic based solar cells.

\section{Acknowledgements}

This work was supported by the National Science Foundation under grant award number CBET1235750 and the Fulbright S\&T award. JM thanks the UGC-INDIA for providing support 
through RAMAN fellowship 2014-2015 to visit Michigan Technological University, USA. Authors also thank Mr. Marikannan and Mr. Patrick for their valuable help with the XRD and AFM and Nupur Bihari with chemical processing.

\section{References}

[1] J. Gwamuri, D. O. Guney, J. M. Pearce, Advances in Plasmonic Light Trapping in Thin-Film Solar Photovoltaic Devices, Solar cell nanotechnology, John Wiley \& Sons, Inc., Hoboken, NJ, USA (2013) 241-269.

[2] J. Trevino, C. Forestiere, G. Di Martino, S. Yerci, F. Priolo, L. Dal Negro, Plasmonicphotonic arrays with aperiodic spiral order for ultra-thin film solar cells, Opt. Express, 20 (2012) 418.

[3] K. Aydin, V.E. Ferry, R.M. Briggs, H.A. Atwater, Broadband, polarization-independent resonant light absorption using ultrathin, plasmonic super absorbers, Nat. Comm., 2 (2011) 517.

[4] H. A. Atwater, A. Polman, Plasmonics for improved photovoltaic devices, Nat. Mater., 9 (2010) 205-213.

[5] V E Ferry, M. A. Verschuuren, H. B. T. Li, E. Verhagen1, R. J. Walters, R. E. I. Schropp, H. A. Atwater, A. Polman, Light Trapping In Thin Film Plasmonic Solar Cells, Proc. 25th EUPVSEC Conference, Valencia, (2010) 6-10.

[6] S. Pillai, M. A. Green, Plasmonics for photovoltaic applications, Sol. Energy Mater. Sol. Cells, 94 (2010) 1481-1486.

[7] C. Wu, Y. Avitzour, G. Shvets, Ultra-thin wide-angle perfect absorber for infrared frequencies, Proc. of SPIE, 7029 (2008) 70290.

[8] Mehta. S. GreenTech Solar. 2010. http://www.greentechmedia.com/articles/read/theprospects-of-amorphous-silicon-down-but-hardly-out.

[9] D. L. Staebler, C. R. Wronski, Reversible conductivity changes in discharge-produced amorphous Si, Appl. Phys. Lett., 31 (1977) 292-294.

[10] H. Kakinuma, S. Nishikawa, T. Watanabe, Thickness dependence of Staebler-Wronski effect in a-Si: H, J. non-Cryst. Solids, 59 (1983) 421-424.

[11] H. Fritzsche, Development in understanding and controlling the Staebler-Wronski effect in a-Si: H, Ann. Rev. of Mater. Res., 31 (2001) 47-79.

[12] R. J. Koval, J. M. Pearce, A. S. Ferlauto, R. W. Collins, C. R. Wronski, Evolution of the mobility gap with thickness in hydrogen-diluted intrinsic Si: H materials in the phase transition region and its effect on p-i-n solar cell characteristics. MRS Proceedings, 664 (2001).

[13] M. J. M. Pathak, K. Girotra, S.J. Harrison, J.M. Pearce, The effect of hybrid photovoltaic thermal device operating conditions on intrinsic layer thickness optimization of hydrogenated amorphous silicon solar cells. Sol. Energy, 86 (2012) 2673-2677.

[14] H.W. Deckman, C.R. Wronski, H. Witzke, E. Yablonovitch, Optically enhanced amorphous silicon solar cells. Appl. Phys. Lett., 42 (1983) 968-970.

[15] T. Tiedje, B. Abeles, J.M. Cebulka, J. Pelz, Photoconductivity enhancement by light trapping in rough amorphous silicon. Appl. Phys. Lett., 42 (1983) 712-714.

[16] A.Vora, J Gwamuri, J.M. Pearce, P. L. Bergstrom, D. O. Guney, Multi-resonant silver nanodisk patterned thin film hydrogenated amorphous silicon solar cells for SWE compensation, J. Appl. Phys., 116 (2014) 093103.

[17] A. V. Zayats, I. I. Smolyaninov, A. A. Maradudin, Nano-optics of surface plasmon polariton, Phys. Rep., 408 (2005) 131-314.

[18] H. A. Atwater, The Promise of Plasmonics, Scientific American, 296 (2007) 56-62. 
[19] S. A. Maier, Plasmonics: Fundamentals and Applications. Springer, 2007.

[20] J. Gwamuri, A. Vora, R. R. Khanal, A. B. Phillips, M. J. Heben, D. O. Guney, P. L. Bergstrom, A. Kulkarni, J. M. Pearce, Limitations of Ultra-Thin Transparent Conducting Oxides (TCOs) for Integration into Plasmonic-Enhanced Thin Film Solar Photovoltaic Devices, 2015 (under review).

[21 A. Vora, J. Gwamuri, N. Pala, A. Kulkarni, J. M. Pearce, D. O. Guney, Exchanging ohmic losses in metamaterial absorbers with useful optical absorption for photovoltaics, Sci. Rep., 4 (2014) 4901.

[22] M. A. Green and S. Pillai, Harnessing plasmonics for solar cells. Nature Photonics, 6(3), (2012). 130-132.

[23] S. A. Maier, H. A. Atwater, Plasmonics: Localization and guiding of electromagnetic energy in metal/dielectric structures, J. Appl. Phys., 98 (2005) $011101-011101$.

[24] M. Marikkannan, M. Subramanian, J. Mayandi, M. Tanemura, V. Vishnukanthan , J. M. Pearce, Effect of ambient combinations of argon, oxygen, and hydrogen on the properties of DC magnetron sputtered indium tin oxide films, AIP Advances 5 (2015) 017128.

[25] Rein, Margrethe Holmer, PhD. Thesis, submitted to University of Oslo, Norway 2015.

[26] S.A. Knickerbocker, Ph.D. Dissertation, Michigan Technological University, 1995.

[27] T.S. Lim, M.S. Thesis, Michigan Technological University, 1997.

[28] M. Logue. Indium-Tin-Oxide (ITO) Etchant Mixture Standard Operating Procedure.

Available at; http://ssel-sched.eecs.umich.edu/wiki/Public.ITO\%20Etching.ashx

[29] E. Palik, Handbook of Optical Constants of Solids (Academic Press, Orlando, 1985), pp.

355-357.

[30] http://rredc.nrel.gov/solar/spectra/am1.5/

[31] L. A. Ryabova, V. S. Salun, I. A. Serbinov, Transparent conductive films of $\operatorname{In}_{2} \mathrm{O}_{3}: \mathrm{Sn}$ prepared by the pyrolysis method, Thin Solid Films, 92 (1982) 327-332.

[32] A.K. Kulkarni, K. H. Schulz, T.S. Lim, M. Khan, Electrical, optical and structural characteristics of indium-tin-oxide thin films deposited on glass and polymer substrates, Thin Solid Films (1999) 345.

[33] D.H. Kim, M.R. Park, G.H. Lee, Preparation of high quality films ITO films on plastic substrates using Rf magnetron sputtering, Surface \& Coatings Technology 201 (2006) 927-931 


\section{Figure Captions}

Fig. 1. (a). Plasmonic solar cell structure, and (b). Reference cell. ARC refers to anti-reflecting coating.

Fig. 2 (a) Resistivity and (b) transmittance of as-deposited and annealed films as a function of oxygen flow rate. Annealing temperature was $300^{\circ} \mathrm{C}$.

Fig. 3. XRD analysis of selected (a) as-deposited and b) annealed ITO film for various oxygen flow.

Fig. 4. XRD analysis of selected (a) as-deposited and b) annealed ITO film for various oxygen flow.

Fig. 5. Variation of (a) sheet resistance with film thickness for ITO (A2) films; (b) annealed ITO film (A2) thickness with etch time.

Fig. 6. Shows the AFM images of the ITO sputtered film on silicon with oxide layer (a), annealed at $300^{\circ} \mathrm{C}$ for $30 \mathrm{~min}$. (b), Annealed film etched for $30 \mathrm{sec}$. (c) etched for $60 \mathrm{sec}$. (d) etched for $660 \mathrm{sec}$. (e) illustration of etching time (sec.) vs. roughness in $\mathrm{nm}$.

Fig. 7. Optical microscope image on the surface of as-deposited (a) and etched for $660 \mathrm{sec}$. (b) ITO thin films on the $\mathrm{Si} / \mathrm{SiO}_{2}$ substrate.

Fig. 8. Numerical simulation results of a-Si:H PV devices. (a). Variation of absorbance with ITO layer thickness for the $300-730 \mathrm{~nm}$ wavelengths, (b). Variation of absorbed power density in ia-Si:H (W/m ${ }^{2}$ with ITO thickness and, (c). Dependence of optical enhancement in the a-Si:H solar cell on ITO spacer thickness for 70 and $80 \mathrm{~nm}$ reference solar cell structures. Both reference cells have no nano-disc plasmonic structure (Fig. 1(b)). 
Table 1. Summary of ITO processing parameters.

\begin{tabular}{|c|c|c|c|c|c|c|c|}
\hline \multirow[t]{2}{*}{$\begin{array}{c}\text { Sample } \\
\text { ID }\end{array}$} & \multirow[t]{2}{*}{$\begin{array}{l}\text { RF } \\
\text { (W) }\end{array}$} & \multirow{2}{*}{$\begin{array}{c}\text { Gas } \\
\text { ratio } \\
\left(\mathrm{Ar}: \mathrm{O}_{2}\right)\end{array}$} & \multirow{2}{*}{$\begin{array}{c}\text { Film } \\
\text { Thickness } \\
\text { (nm) }\end{array}$} & \multicolumn{2}{|c|}{ 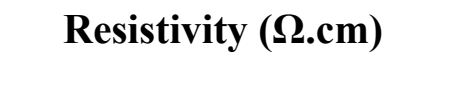 } & \multicolumn{2}{|c|}{$\begin{array}{c}\text { Average transmittance } \\
(400-800 \mathrm{~nm})\end{array}$} \\
\hline & & & & $\begin{array}{c}\text { As - } \\
\text { deposited }\end{array}$ & $\begin{array}{c}\text { Annealed at } \\
\text { 300 } \mathrm{C} \\
(\mathbf{3 0 m i n})\end{array}$ & $\begin{array}{c}\text { As - } \\
\text { deposited }\end{array}$ & $\begin{array}{c}\text { Annealed at } \\
\text { 300 }^{\circ} \mathrm{C} \\
(30 \mathrm{~min})\end{array}$ \\
\hline $\mathrm{A} 1$ & 100 & 10:0 & 98 & $1.6 \mathrm{E}-02$ & $8.8 \mathrm{E}-04$ & 60 & 70 \\
\hline A2 & 100 & $10: 0.2$ & 85 & $5.0 \mathrm{E}-03$ & $5.5 \mathrm{E}-04$ & 72 & 79 \\
\hline A3 & 100 & $10: 0.3$ & 78 & $1.8 \mathrm{E}-03$ & $5.7 \mathrm{E}-04$ & 65 & 71 \\
\hline A4 & 100 & 10:0.4 & 87 & $2.4 \mathrm{E}-03$ & $8.0 \mathrm{E}-04$ & 85 & 91 \\
\hline A5 & 100 & $10: 0.5$ & 89 & $6.7 \mathrm{E}-03$ & $1.6 \mathrm{E}-03$ & 84 & 88 \\
\hline A6 & 100 & $10: 0.7$ & 64 & 4.3E-02 & $1.7 \mathrm{E}-02$ & 86 & 92 \\
\hline A7 & 100 & $10: 1.0$ & 63 & 4.7E-01 & $5.2 \mathrm{E}-02$ & 86 & 94 \\
\hline
\end{tabular}


Table 2. Summary of XRD analysis of selected ITO film samples

\begin{tabular}{|c|c|c|c|c|c|c|}
\hline Sample code & \multicolumn{2}{|c|}{ d spacing $(\AA)$} & \multicolumn{2}{l|}{ Lattice constant $(\AA)$} & $\mathbf{I}_{222} / \mathbf{I}_{400}$ & $\begin{array}{c}\text { Grain } \\
\text { size } \\
(\mathbf{n m})\end{array}$ \\
\hline & $\mathbf{2 2 2}$ & $\mathbf{4 0 0}$ & $\mathbf{2 2 2}$ & $\mathbf{4 0 0}$ & & \\
\hline Standard & 2.921 & 2.529 & 10.118 & $\ldots \ldots \ldots$ & 3.33 & $\ldots \ldots$. \\
\hline 0.2 & 2.872 & 2.552 & 11.486 & 10.207 & $\cdots$ & 22 \\
\hline $0.2 \mathrm{~A}$ & 2.921 & 2.531 & 11.685 & 10.124 & 3.99 & 30 \\
\hline 0.3 & 2.951 & 2.551 & 11.804 & 10.205 & 3.69 & 23 \\
\hline $0.3 \mathrm{~A}$ & 2.974 & 2.562 & 11.898 & 10.249 & 1.93 & 14 \\
\hline 0.4 & 2.919 & 2.528 & 11.67 & 10.113 & 2.1 & 26 \\
\hline $0.4 \mathrm{~A}$ & 2.936 & 2.556 & 11.746 & 10.226 & 3.58 & 26 \\
\hline 0.5 & 2.915 & 2.524 & 11.66 & 10.09 & 4.52 & 24 \\
\hline $0.5 \mathrm{~A}$ & 2.920 & 2.535 & 11.676 & 10.113 & 4.68 & 20 \\
\hline
\end{tabular}


Table 3. Etching time and the measured thickness and electrical properties.

\begin{tabular}{|c|c|c|l|}
\hline $\begin{array}{c}\text { Etching } \\
\text { time }\end{array}$ & $\begin{array}{c}\text { Film Thickness } \\
(\mathbf{n m})\end{array}$ & $\begin{array}{c}\text { Sheet resistance } \\
\mathbf{\Omega} / \mathbf{S q}\end{array}$ & $\begin{array}{l}\text { Resistivity } \\
\mathbf{( \Omega . c m})\end{array}$ \\
\hline 0 & 85 & 70 & $5.6 \mathrm{E}-04$ \\
\hline 30 & 81 & 66 & $5.4 \mathrm{E}-04$ \\
\hline 60 & 78 & 68 & $5.3 \mathrm{E}-04$ \\
\hline 240 & 63 & 95 & $6.0 \mathrm{E}-04$ \\
\hline 360 & 54 & 105 & $5.7 \mathrm{E}-04$ \\
\hline 510 & 44 & 154 & $6.8 \mathrm{E}-04$ \\
\hline 660 & 36 & 250 & $9.0 \mathrm{E}-04$ \\
\hline
\end{tabular}




\section{Ag Nano-disc (diameter- $240 \mathrm{~nm}$ )

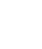

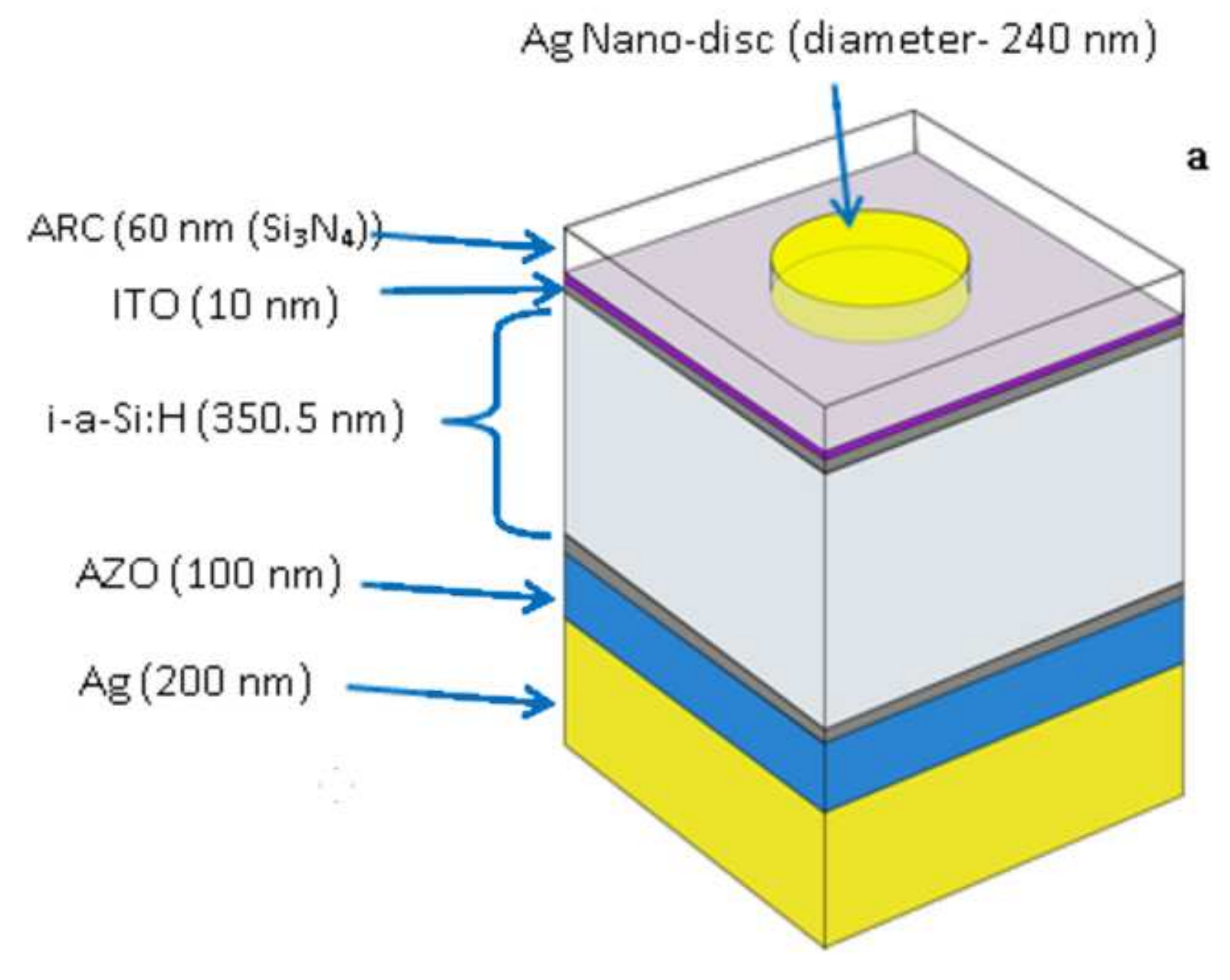

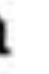

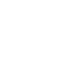

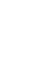



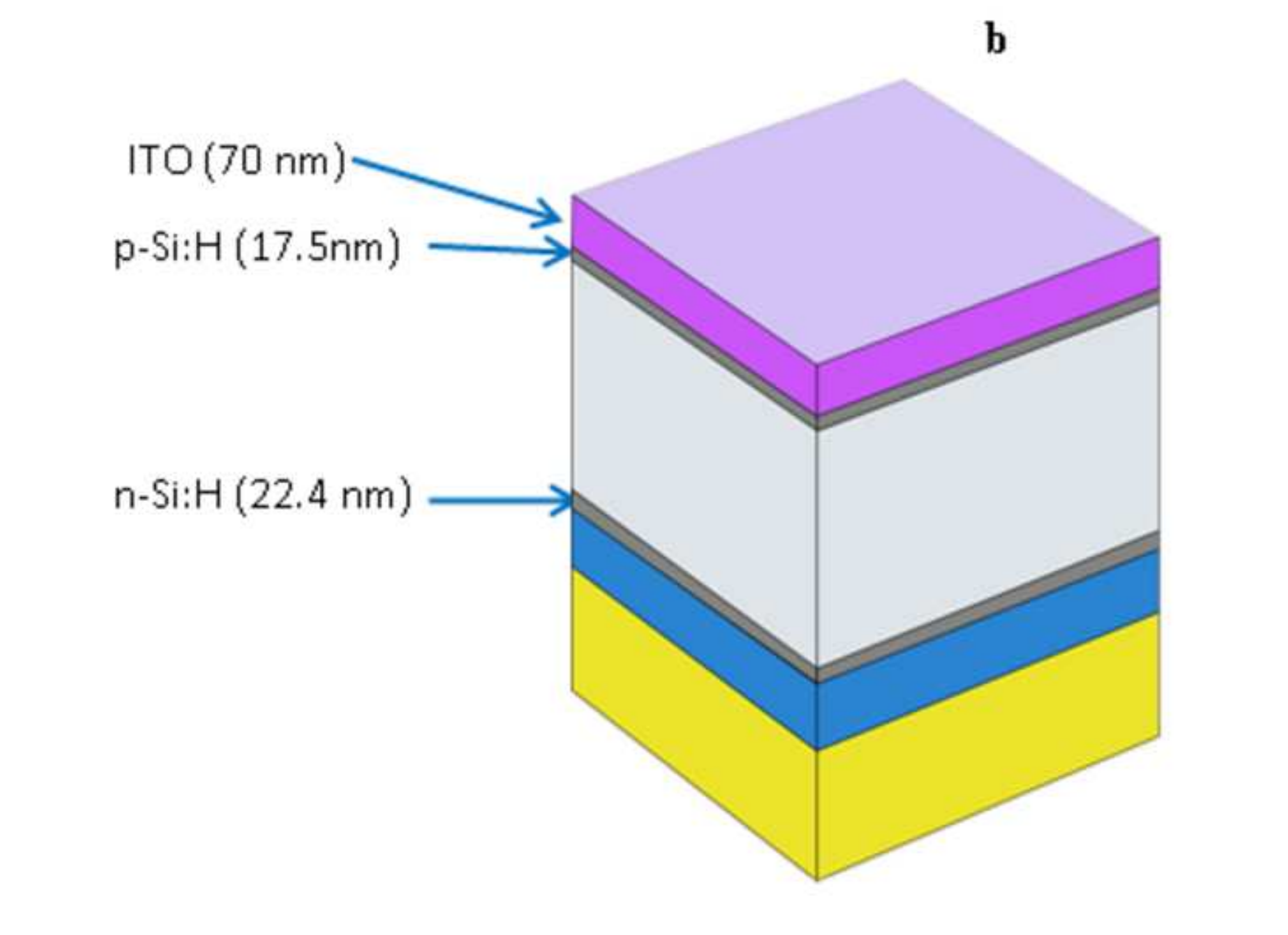

.




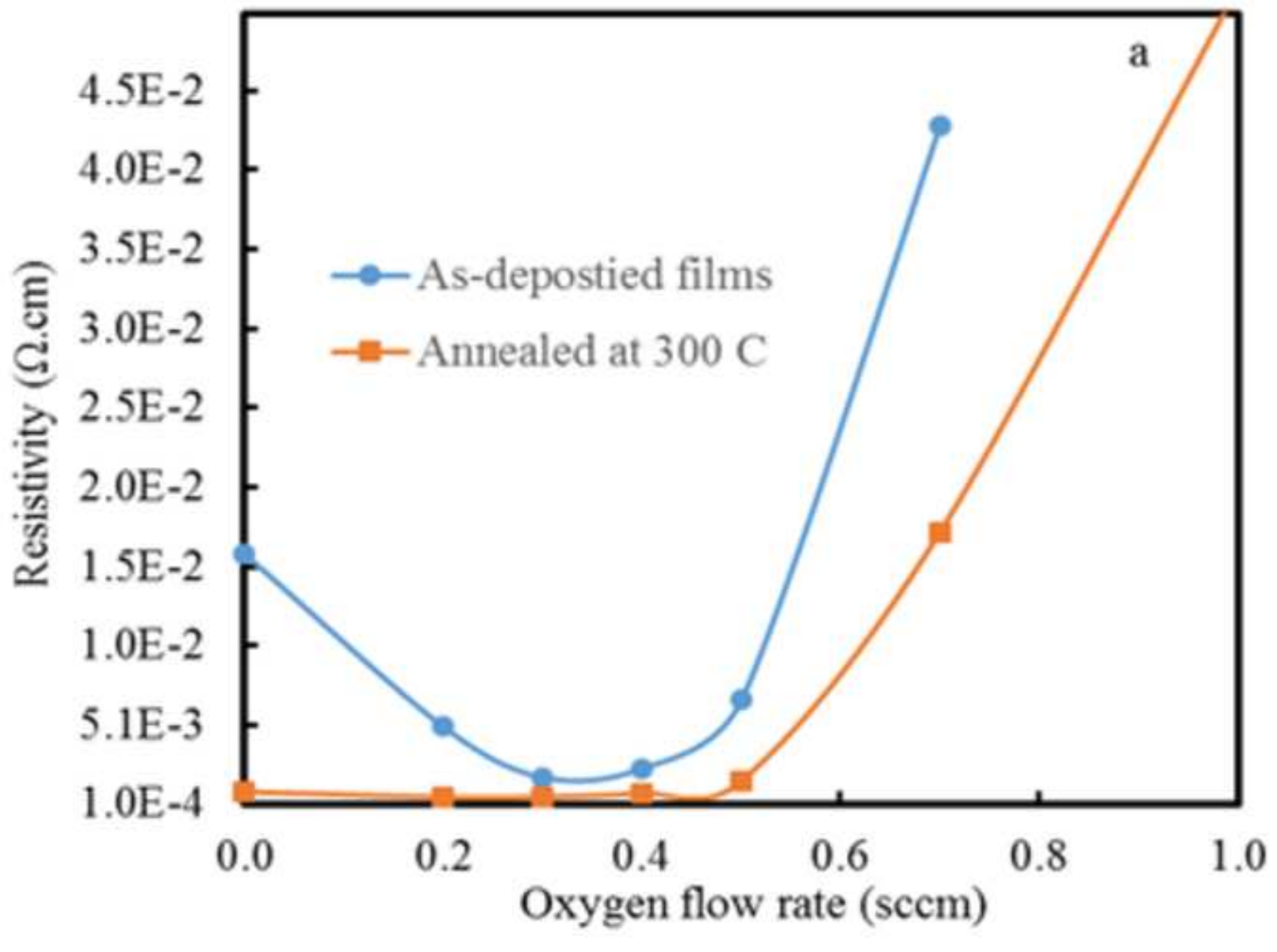




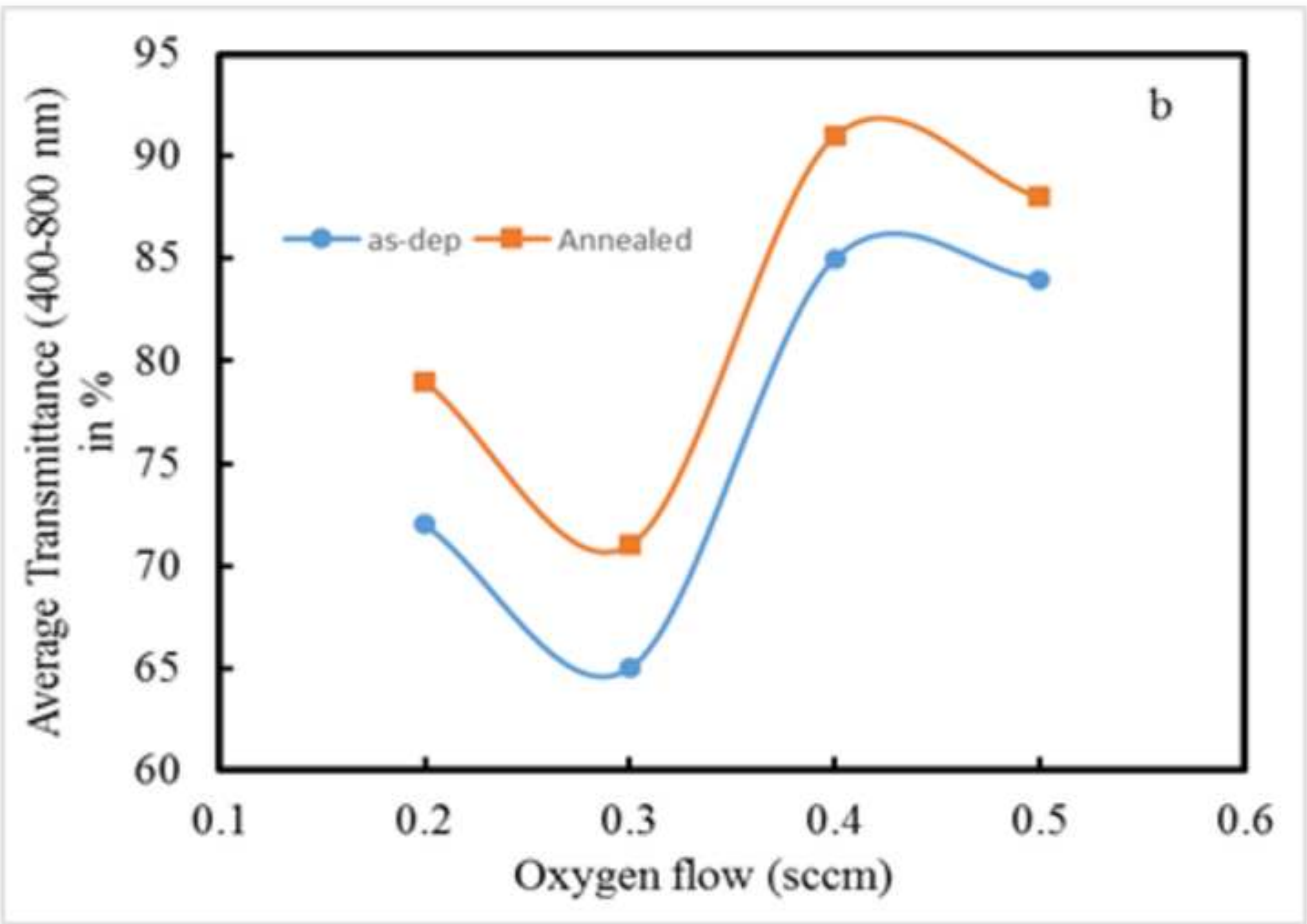




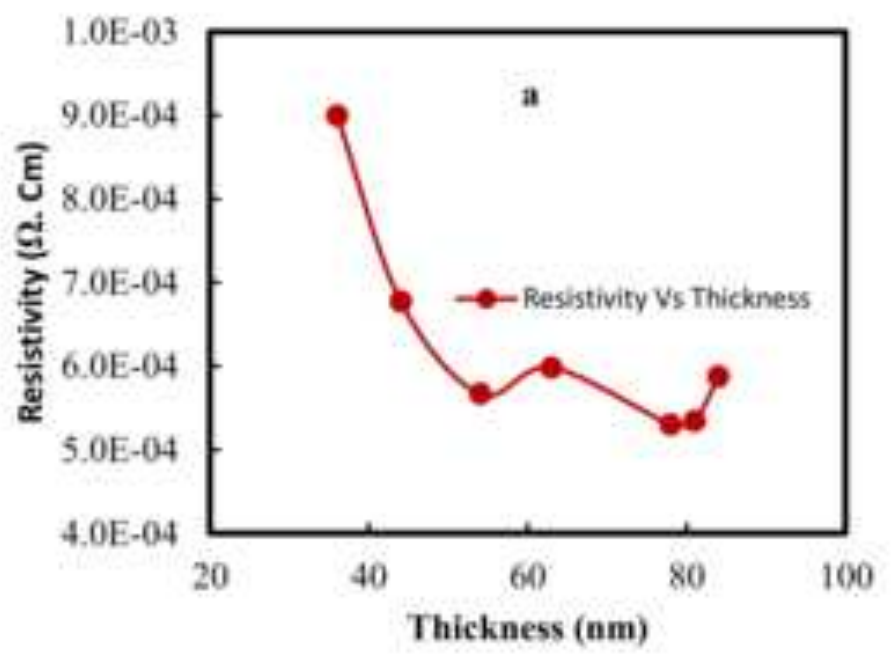

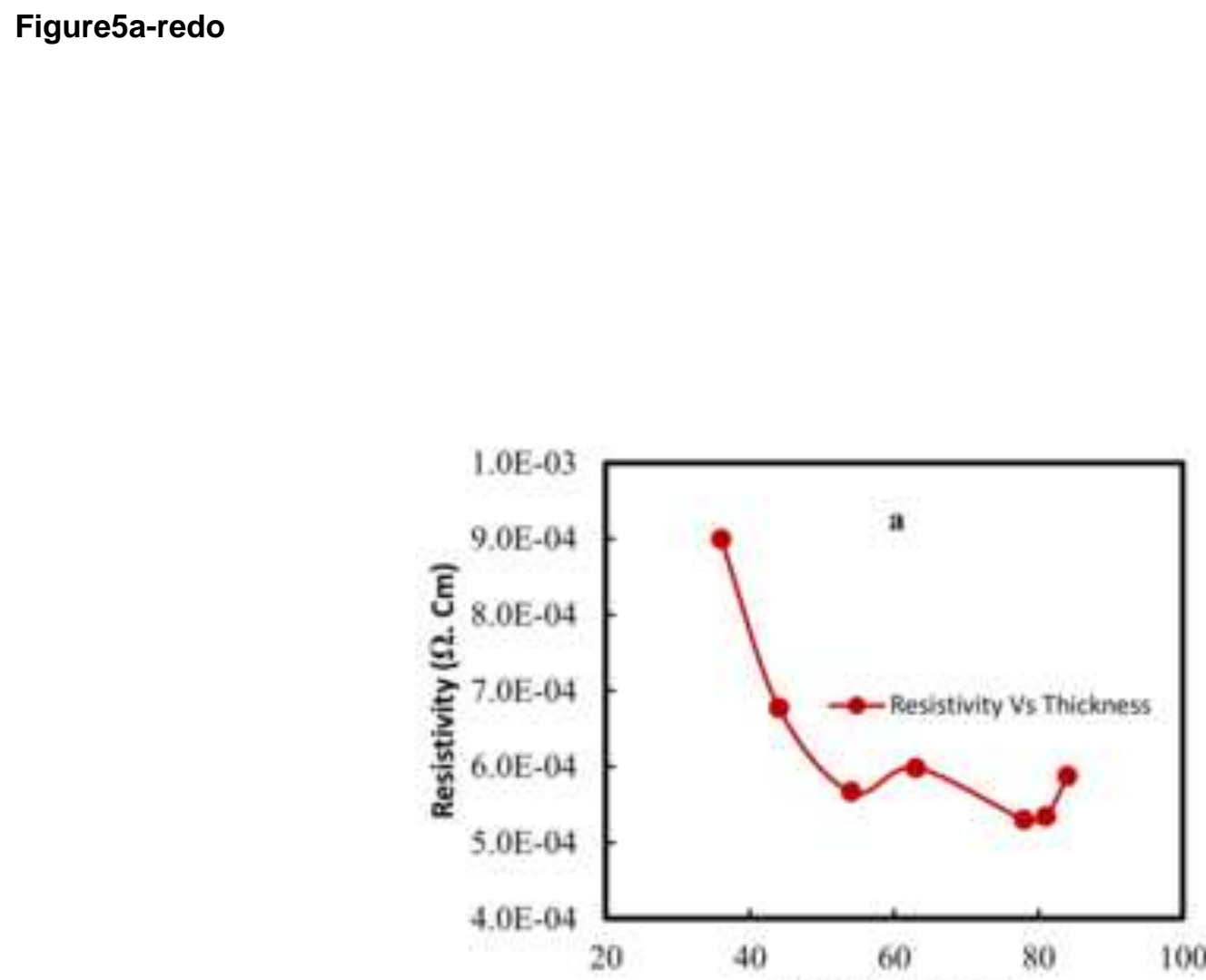

Thickness (nm) 


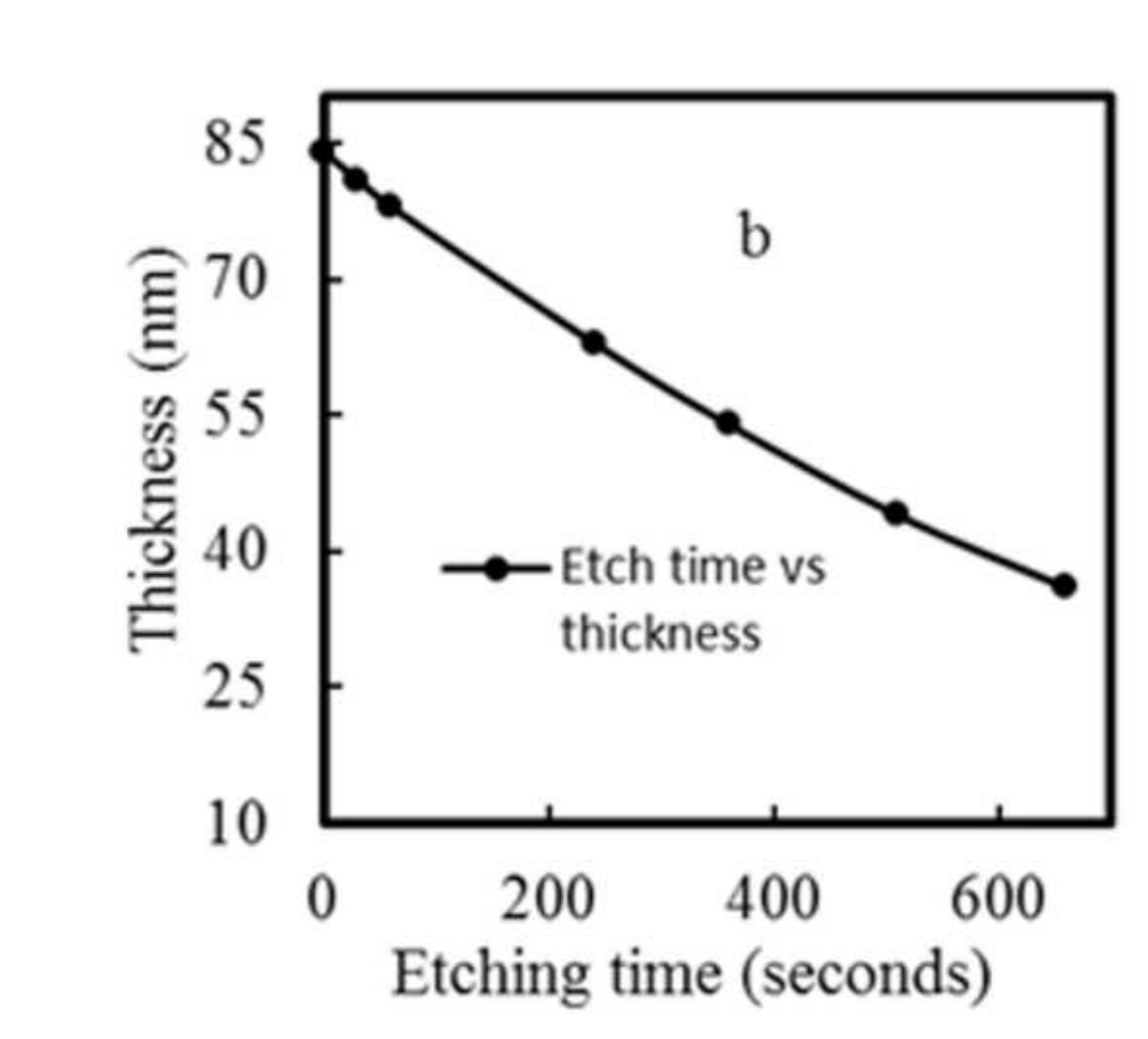

fig. 5.b.ti

.

.



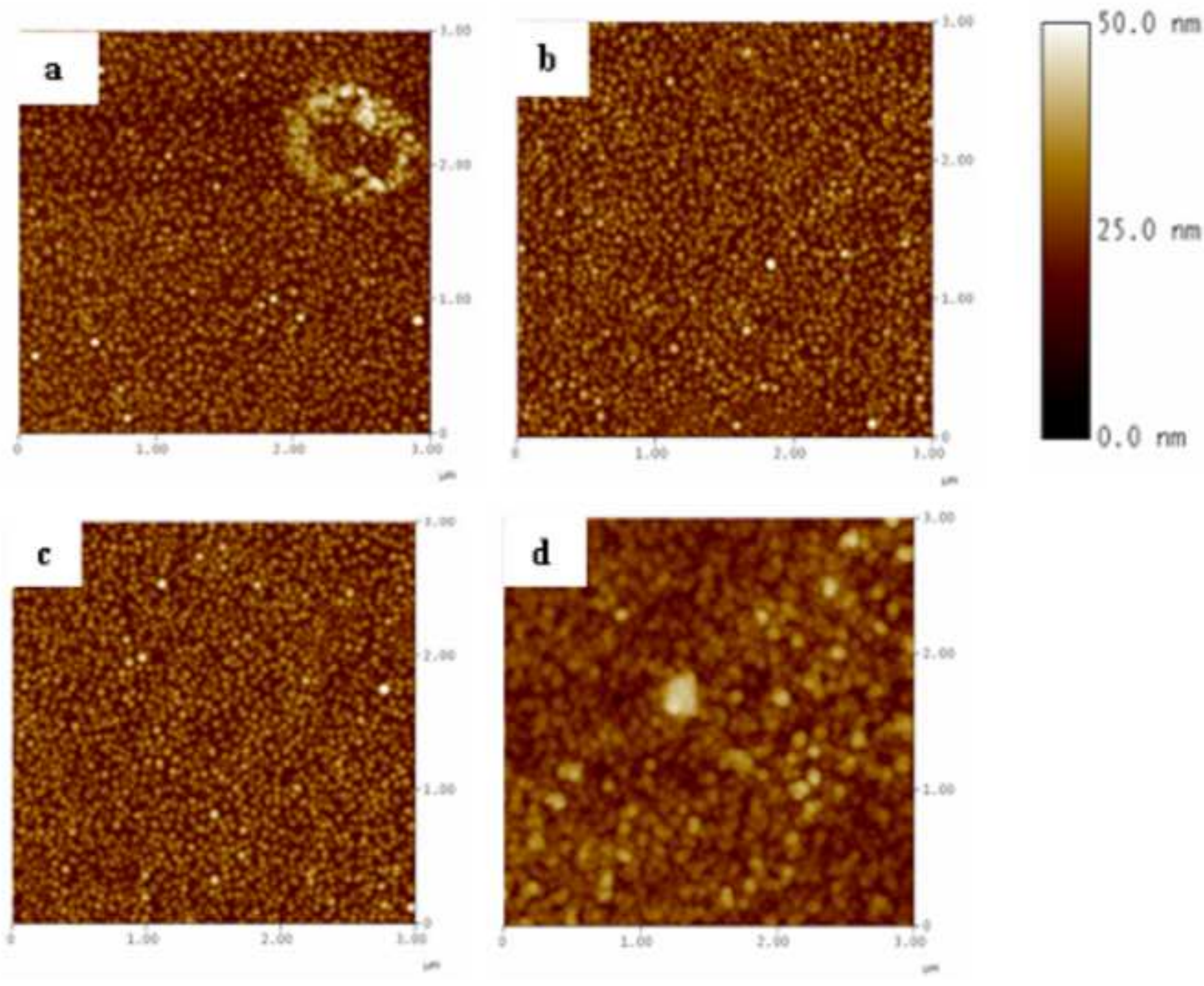


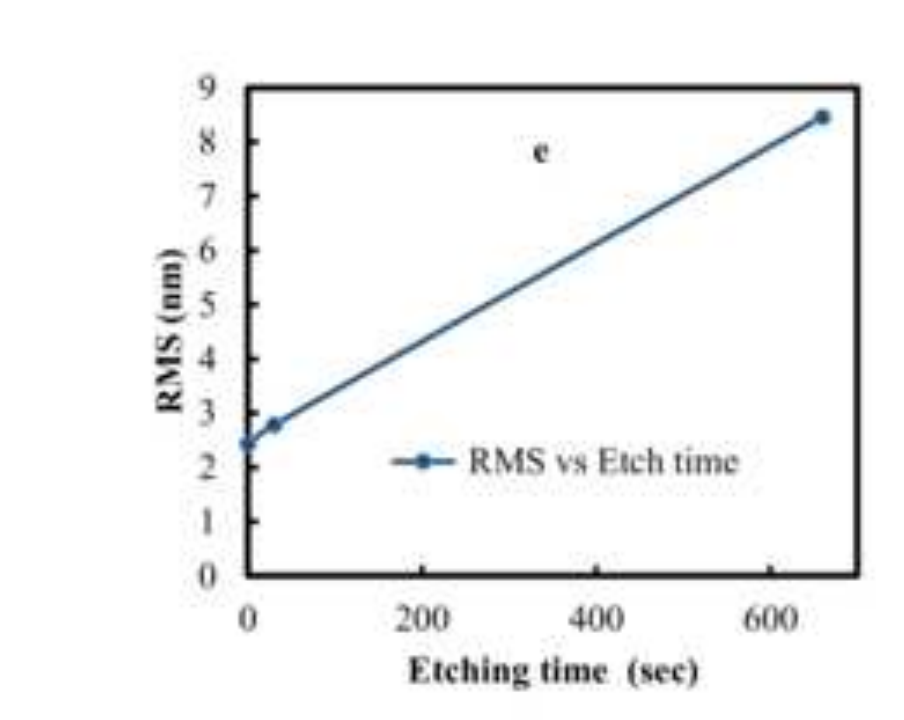

Figure6e-redo

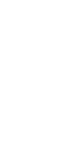
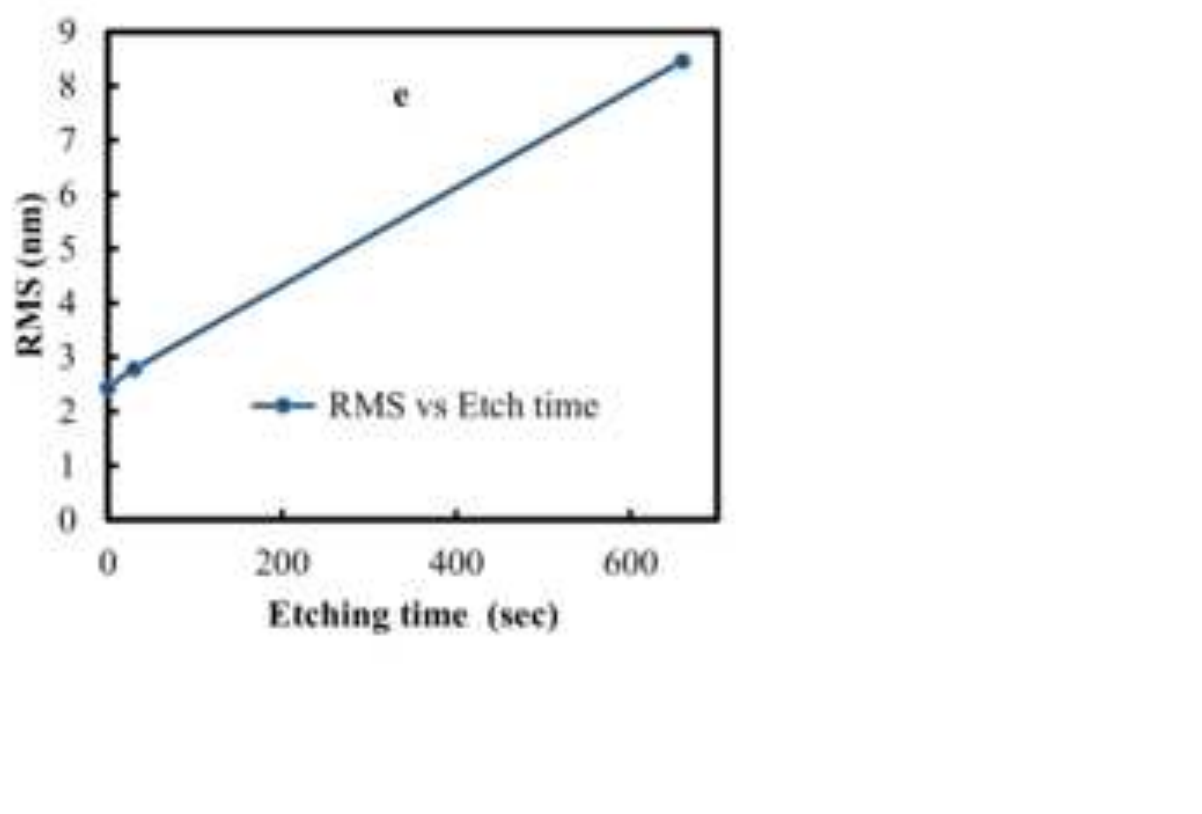
.

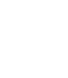
.

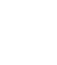
. . .

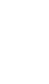

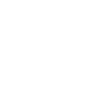
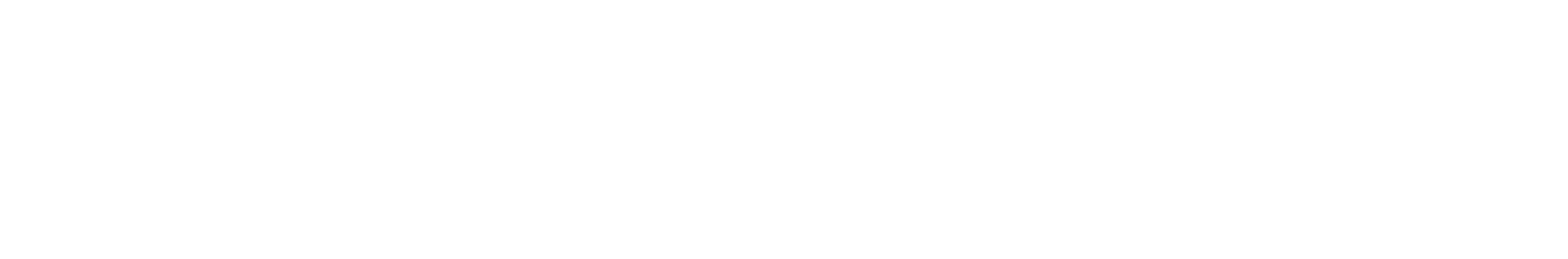


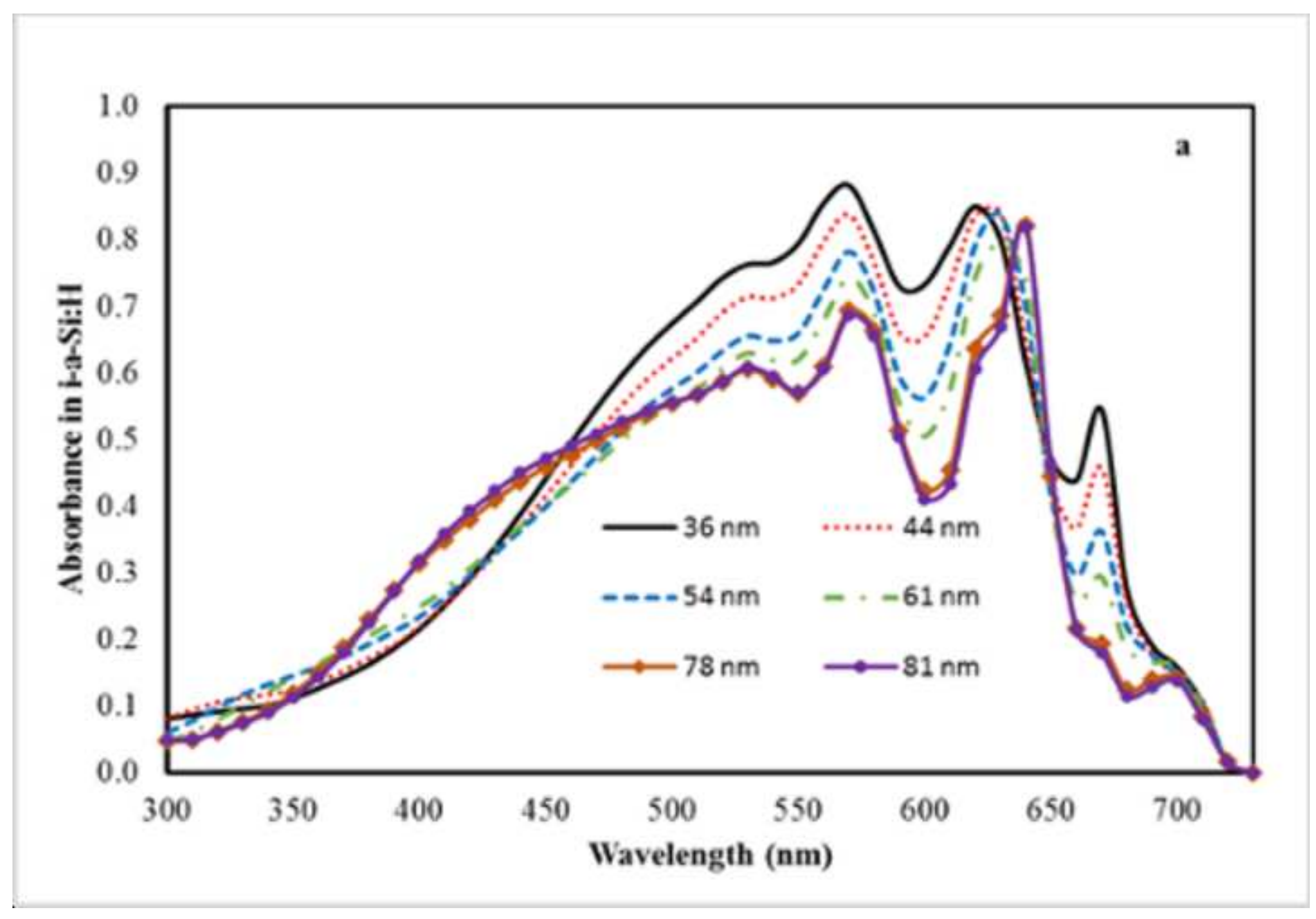



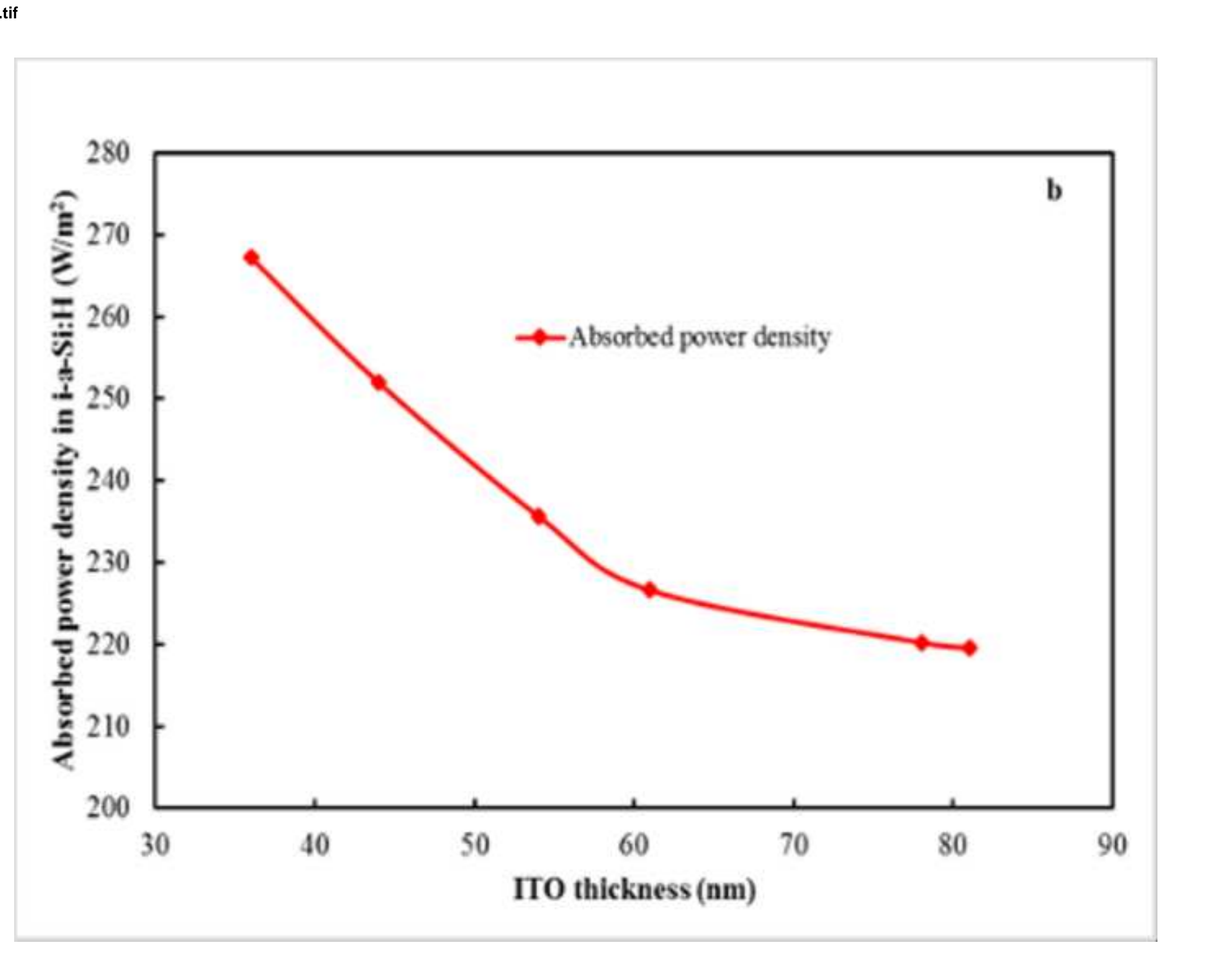

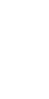

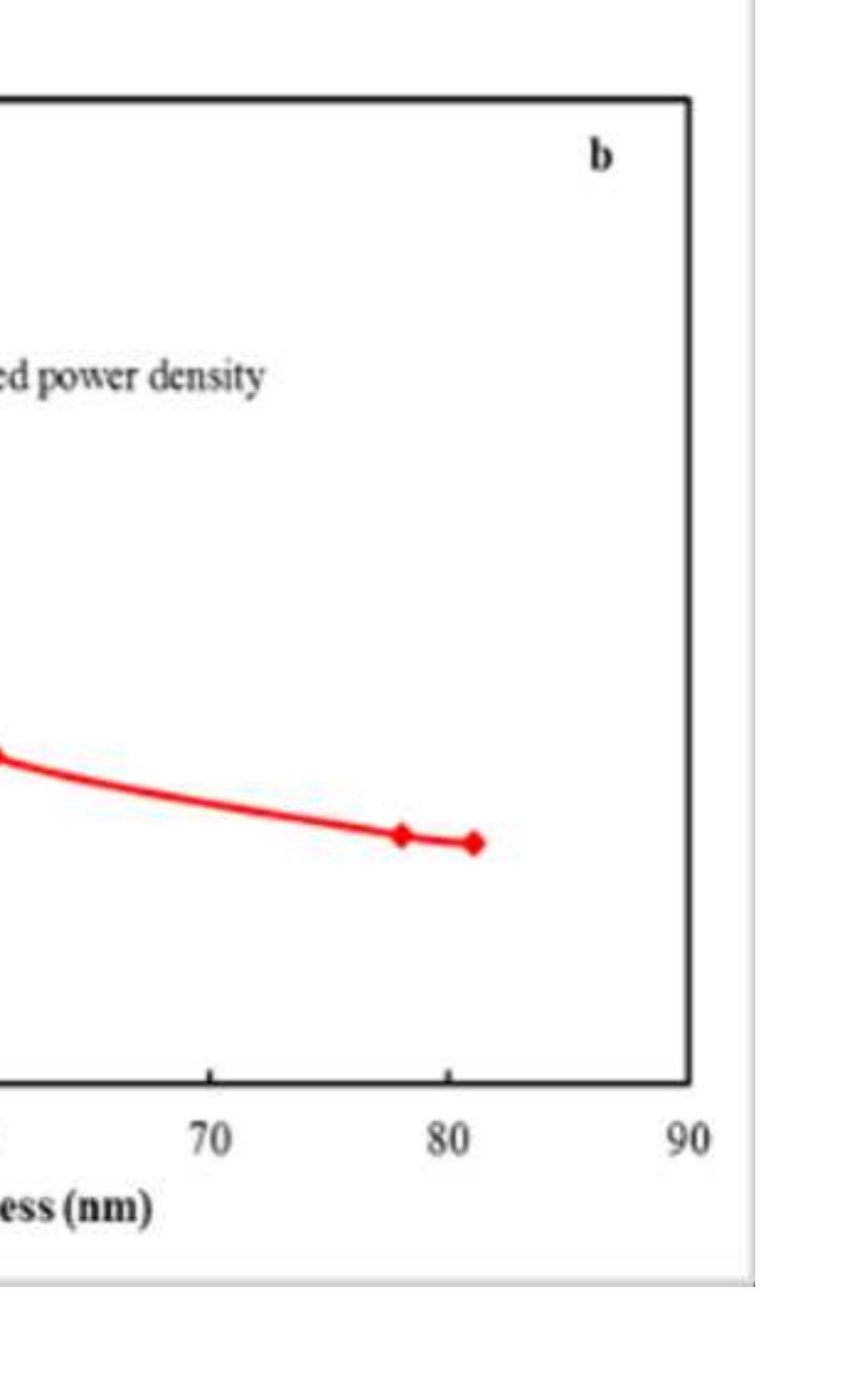




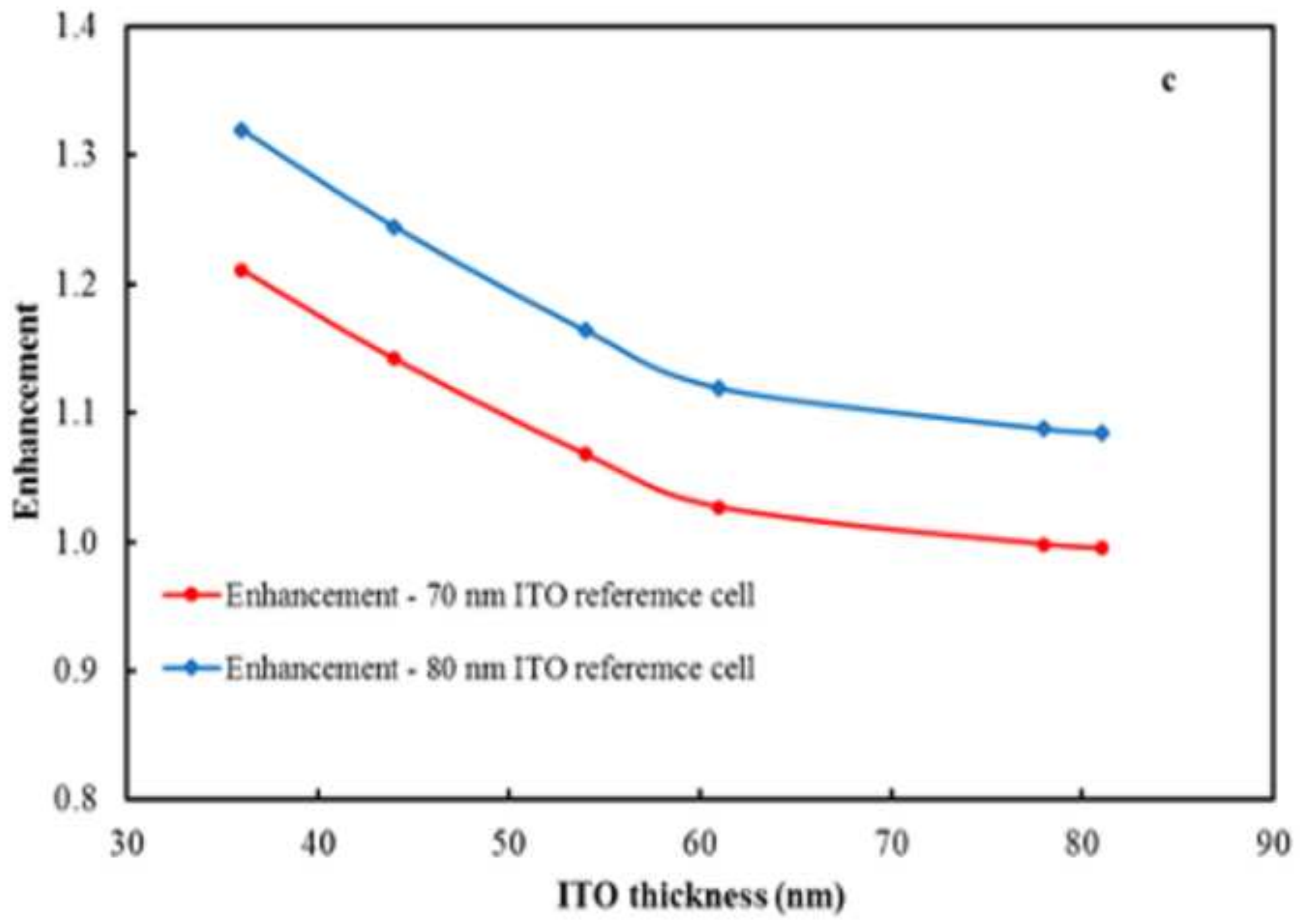

